\title{
Erotic Life as a New Frontier in $\mathrm{HCl}$
}

\author{
Olav W. Bertelsen \& Marianne Graves Petersen \\ University of Aarhus, Department of Computer Science \\ Aabogade 34, DK-8200 Aarhus N, \\ Denmark \\ \{olavb, mgraves\}@daimi.au.dk
}

\begin{abstract}
In this paper we discuss how information technology impacts erotic life. This has been a neglected issue in most of the literature, even the literature on IT in the home. We argue that current IT, in particular in the home, tends to marginalize erotic aspects of life, through developing domestic technology, without considering how it impacts conditions for erotic life in the home. We suggest the need for a counter discourse in HCI, and we outline a number of theoretical and empirical perspectives, which can contribute to establish erotic life as a new frontier in HCI.
\end{abstract}

\section{Categories and Subject Descriptors}

H.1.2 User/Machine Systems.

\section{General Terms}

Design, Human Factors.

\section{Keywords}

Erotic life, aesthetics, communication, visibility and invisibility, interactive spaces, life quality, workplace rationality.

\section{INTRODUCTION}

The field of HCI is increasingly becoming interested in the field of the home as a site for design of technology. This has been seen as an interesting site, since it provokes the rationalities of designing for a workplace [7][18], the domain out of which HCI was born and has developed from. However, apart from the $\mathrm{CHI}$ 2006 workshop [6], a perspective on sex and eroticism is almost totally absent. To clarify, we see erotic life as embracing a spectrum from the erotic atmosphere (or ambience) via the light flirt, to the concrete conditions for realizing the sexual intercourse.

Basically, there are two ways of looking at how domestic design influences everyday erotic life. One approach is to focus on designing interactive technologies to support erotic experiences, and a second strategy is to look at how the design of mundane everyday technologies influences conditions for erotic life. Some

\footnotetext{
(c) Olav W. Bertelsen \& Marianne Graves Petersen, 2007 Published by the British Computer Society Volume 2 Proceedings of the 21 st BCS HCI Group Conference

HCI 2007, 3-7 September 2007, Lancaster University, UK Devina Ramduny-Ellis \& Dorothy Rachovides (Editors)
}

people do involve interactive technology in their erotic life, but so far this area has received very little attention from the HCI research community; [6] is one example though.

The second issue we cannot escape as a community, but so far we see only few attempts in this direction. As an example, there is an increasing interest in introducing sensor technologies in the home, e.g. to infer availability status [11]. Such systems impact conditions for exercising erotic life, but this issue is not even touched upon nor linked to the issue of availability. Thus, as technology becomes more and more ubiquitous, we have to consider erotic life as part of our understanding of humancomputer interaction, in order to avoid designing sterile deserts.

In much research on domestic computing, it seems as if the ideals of efficiency and the focus on tasks seamlessly has drifted into the domestic computing area [18], even though there have been a number of warnings against this tendency [18][7]. The focus on erotic life is a useful provocation in maturing the field of HCI to truly embrace the characteristics of home life and felt life [13], as it inherently provoke ideals from the workplace, as this is perhaps the most inefficient and non-work activity taking place in a domestic context.

In designing IT-based artefacts various quality criteria may apply. One example is effectiveness, efficiency and satisfaction as laid out in the usability standards. However, going back to the birth of participatory design, some higher level values was proposed as the ideals to work from with respect to technology design. These included the ideal of improved life quality [9]. More recently, it has been pointed out how this perspective is relevant, if not urgently needed in the development of future domestic technology too [12]. Thus if we are willing to take a broader perspective, it is hard not to adopt quality of life as a basic principle. Already wellestablished accounts on humanistic psychology have hinted that sexual satisfaction is important for a complete life. More recent positions have also established a well functioning sexual life as an important aspect of a "good life" [23]. Thus, adopting a perspective of life quality in technology development implies that quality of erotic life should also be accounted for.

Most approaches to technology mediated erotic activity in the past seem to have centered around futuristic concepts such as cyber sex, where sexual activities would be carried out in virtual reality with the users hooked up via direct stimulation of erogenous zones. In contrast, we aim to look into eroticism, and sexual practice, as aspects of everyday life not necessarily directly designed for in the development of information technology, but still changed massively as technology is becoming present in the private and intimate sphere. A recent investigation suggested that couples that have television in their bedroom have sexual intercourse half as often as those who do not [20]. On the other 
hand the TV set can also be used for watching pornography as inspiration or as part of the sexual activity. So obviously, the issue is complex, and technology can serve as an enabler as well as a disabler. That is, sometimes the effects of the new technologies are positive, but most often it seems that intimacy is jeopardized as these workplace centric technologies invade private life. This is a problem, as it seems that many of the new technologies entering into the private space (in combination with an intensified working life) are significant factors in making sexual life difficult for many couples today. What is striking in the context of HCI, however, is that investigations on how technology design influences our erotic life, let alone make way for new erotic experiences, is almost completely absent from the research field. With this paper, we propose to start such investigation. As a first step towards a foundation for erotic life in HCI, we outline and discuss a series of relevant themes.

\section{AESTHETICS IN EROTIC LIFE}

Recently, the field of HCI has opened up to cover new perspectives like emotion and aesthetics. This is partly a result of acknowledging that the increasing permeation of technology into everyday life creates a need for new perspectives to understand, design and evaluate human-computer interaction. Several authors have pointed out that aesthetics is becoming a necessary and integral part of HCI [3] [4] [14] [19] [22]. This turn is not only motivated by the fact that HCI is becoming relevant in new settings, but as much in a theoretical need to understand the dynamics of the use situation [2][4].

Eroticism has been a central concept in modern aesthetic theory denoting the non-interpretable and immediate counterpoint to the hermeneutic [5]. Erotic experience has also been a key theme in many artworks. As in Baudelaire's poem "to a passer-by":

\section{A lightning flash... then night! Fleeting beauty}

By whose glance I was suddenly reborn,

Will I see you no more before eternity? [1]

This excerpt of the poem points to the erotic moment as being fundamentally mysterious and contingent. The moment is irreversible and irretrievable and cannot be captured by reasoning. This erotic moment results in an instantaneous reshaping of the two involved persons. The erotic glance is out in the open, to be seen by anyone, but only perceivable for the relevant other person. The poem highlights the intensity of the experience that is shared between these two people only. It is a secret layer in an everyday, public situation that for the involved man and women is a unique experience. Where the modern aesthetics represented by Baudelaire emphasizes the unique and shocking, even if it is achieved by glancing out of the tram, the current aesthetic wave in HCI is to a large extend based on a pragmatist approach emphasizing the bodily mundane [14][19][21].

Aesthetics is potentially a fruitful perspective for understanding the more sensitive aspects of computing [14]. From this perspective it has been highlighted how interaction design should consider all human senses and the whole body in the design.

From the pragmatists perspective, Shusterman [21], points out that aesthetic experience offers a fruitful perspective on erotic experience. In opposition to the awkward way western society treats sex and eroticism, he argues that western modernity at large tends to treat sex in a distinctly medical rather than aesthetic perspective. As an alternative he promotes aesthetic experience as a basis for understanding erotic life: “...seeing erotic experience as aesthetic experience has more than theoretical consequences. It can inspire us to greater aesthetic appreciation of our sexual experience, and consequently, to more artistic and aesthetically rewarding performance in our erotic behavior, which surely forms one important dimension of the art of living”. [[21] p. 227].

\section{INTIMACY IN FAMILY LIFE}

Within the fields of sociology and psychology, a number of investigations have been undertaken around human erotic life. The challenge for HCI is to investigate these with the aim of pointing to implications for technology design, or alternatively perform new investigations that address the relation between erotic experiences and technology design. Looking to established HCI-based research of home life, design patterns have been suggested as a fruitful approach to draw implications from empirical studies of domestic life for technology design [7]. However, until now the patterns developed have not covered intimate and erotic situations.

Broader studies of modern family life can also point to findings relevant for future technology design. A recent Danish survey around the changing conditions for family life [8] highlighted how postmodern family life, where people are part of multiple and changing social groups and possibly live in changing and network families, make an improved pressure on the family as a site for true intimate relations:

“... establishing close relationships based on common experiences demands much more of the family members. In other words, family members can no longer be guided by traditions. In order to lead a fulfilling family life, its members will need to rely increasingly on their capacity to reflect continuously on their social relationships and actively to construct commonality" [8].

The family becomes a kind of specialized sanctuary for intimacy. While this holds for the family as a whole, this must also concern the partners. Domestic computing research around connecting, people who live apart, to some extend addresses this issue [17]. However, the paradigm of anything, anywhere anyhow is a double-edged sword in this respect, as it holds for lovers as well as for others, and thus may seriously interfere with intimate situations. Furthermore, it has been pointed out that the increasing fraction of families where both adults work full time tend to shift their relationship into one where negotiations around time, and the right to work more and more hours take up a lot of attention [7] [8]. In an American context, Hochschild [11] has illustrated how people seem to be caught in a time trap when work becomes family and family becomes work. At work, there is a focus on self-realization and social relationship with colleagues, whereas home life concentrates on the practical tasks, which need to be accomplished and which are increasingly outsourced.

Thus, a design approach to addressing this challenge is to design for unexpected openings, illogical combinations, which can support erotic impulses and erotic play. The coarse example would be to have a random four hour power outage two times each week (this "approach" at least proved to work during world war two).

\section{COMMUNICATION IN EROTIC LIFE}

According to the general sexology literature, inability to communicate seems to be the most common reason for divorce 
and other problems in intimate relationships [13]. The ability to communicate is not necessarily of key importance in the early phases of a relationship, when sexual tension and the attraction of the opposite are drawing the couple together, but communication patterns established early in the relationship are important later on [ibid]. Differences in vocabulary and the lack of experience in talking about sex are obvious sources for problems in maintaining a sexual relationship. The literature on marriage counseling also points to the general mode of communication as often being problematic, e.g. communication patterns developed between siblings, focusing on blaming the other part, or patterns focusing on winning the argument lead to problems when applied in the relationship.

Interactive technologies present in the home impact communication in several ways. The discussion on the time trap [11] indicates that communication has degenerated into negotiation, substituting intimate communication with technical rationality. The constant opportunity to communicate with people outside the home and the constant stream of media contents seems to be negative factors as pointed out above. A low-tech approach would be to reduce the impact of the disabling technologies, e.g. by cutting off the media stream and by defining specific time slots for external communication. Along the same lines, defining time slots for talking together, or having a shared diary could compensate for the missing communication.

An intimate communications perspective provides a clear departure away form the hegemony of technical rationality, helping the erotic back from its exiled position as residual category.

\section{VISIBILITY OF EROTIC LIFE}

Invisibility is a key factor in ambient technology; the rationale being that with myriads of devices it is required that the technology minds itself without users' intervention. Criticizing this naïve position, the Palcom project [10] has set out from the assumption that technology that just does its' thing independently of users control will not work properly in non-standard situations. The challenge of making systems that provide invisibility with visibility is critical in such situations. As the Palcom project primarily focuses on architectures for ambient computing they take the visibility-invisibility tension in a quite literal and technical meaning. The visibility-invisibility tension is not, however, only a technical issue but also, a personal and relational issue.

The tension between visibility and invisibility is important to erotic life in at least two ways. Firstly, it is related to possible excitements around exhibitionist and voyeuristic flavored experiments. Secondly, it is related to intimacy being exclusive to the involved then requiring a "safe space" and at the same time excluding others. The exploration of this tension in relation to erotic life may provide new insights and strategies for handling visibility and invisibility in general..

\section{EROTIC LIFE AS FUN}

Among the selected findings in a survey of the world sexology literature in 2000, WHO Senior Policy Advisor, Judith Mackay pointed out the following:

"WHERE IS THE FUN? It was surprisingly difficult to find cheerful aspects of sex. Most of what is measured is negative teenage abortions, diseases, child prostitutes, harsh laws, sex crimes such as rape, harassment and stalking. Even the success of sex education is usually measured by the avoidance of unwanted pregnancies and STIs, not by whether children grow up to have a fulfilling sex life." [15]

Our attempts to find inspiration in the sexology literature, lead to similar conclusion. Indeed also our own analysis as presented here in terms of the diagnosis of how erotic life has become a residual category under the hegemonic status of technical rationality, how the inability to communicate leads to marital problems, etc has also focused on the negative. It is, however, important to note that our argument is twofold; in arguing for a discourse in interaction design that both reduces the negative impacts technology and support design of technology that can inspire and enhance erotic life.

\section{CONCLUSIONS}

We have pointed to the complex relation between information technology and erotic life as impacting the quality of human life. Thereby, we claim that this complex should be addressed as a new frontier for HCI. The discussions above open a number of themes that will be relevant for HCI in addressing erotic life. Below we conclude the discussion by outlining the elements of a disciplinary discourse in HCI regarding erotic life

Theoretically and intellectually, we point to perspectives that can frame this complex issue in the field of HCI. Both the pragmatic and the modernist aesthetics have something to offer in this direction. Most importantly, the aesthetic turn breaks fundamentally with the dominating status of technical rationality. For this new discourse, it is also important to integrate knowledge from medical, sociological, sexology, and therapeutic practice dealing with erotic life and its conditions in modern families. There are opportunities for focusing on communication around erotic experiences and for investigating the tension between technologies that are invisible and visible in use. Finally, the emerging interest in designing for fun in HCI can serve to frame a new perspective on designing for erotic life, and the conditions for exercising this in a playful way, rather than the prevalent medical approaches to problems in erotic life, as is highly prevalent in the western world. It is important, also, to realize that many issues related to sex and information technology are not necessarily part of $\mathrm{HCI}$; e.g. various forms of abuse, or the diffusion of pornography through the Internet.

The starting point, for the erotic life-oriented HCI design approach we will suggest, is that we don't think that IT necessarily should have a role in peoples sexual life. Because, however, current technologies do have a negative effect in many cases these effects should be counterbalanced by deliberate design for erotic life. We should avoid solutions that make erotic life difficult, e.g. by extending workplace rationality into the home, and aim for solutions that provide enablers for erotic life activities, e.g. by providing privileged room for intimate communication. We also suggest that designing opportunities for playfulness, unforeseen fun and inventiveness in erotic life activities is important, as a way to help people maintain focus on their marital relation.

Methodically, HCI and interaction design for erotic life is a challenge. We are faced with new criteria that most established methods do not address, and because intimacy is intimate and private, it is by nature difficult for outsiders to observe. We expect that many established methods that address open design 
situations, like rapid prototyping with users and participant observation studies will be awkward to apply in this new field. Other approaches such as dairy based studies, and qualitative interviews are more promising, but should be adapted to the fact that most people consider sex and erotic life very private. Close collaboration with marriage counselors may also be a fruitful method in particular if combined with rapid cycles of design, use and redesign of IT-solutions.

These difficulties also impact the possible approaches to evaluation and validation. The criteria for success are hard to define, as a good erotic life most likely cannot be measured in terms of the frequencies of sexual intercourse in the couple, or other exact measures. For HCI to succeed in this new field collaboration with, and integration of knowledge from other disciplines is important. This may also be a challenge to those disciplines. E.g. medical sexology tends to rely exclusively on epidemiological approaches that are less suited for generating an understanding of the dynamics of intimate relations and the creation of erotic moments. Thus, design for erotic life, will probably provoke development in other disciplines.

For HCI in general erotic life is important in unfolding the experience oriented turn, in addressing the situation of use in a broader perspective, and in provoking the refinement of methods.

\section{ACKNOWLEDGMENTS}

We thank Sofie Beck participating in developing this perspective, and we thank colleagues and students who have helped mature this perspective through engaging and provoking discussions.

\section{REFERENCES}

[1] Baudelaire, C., (1857). Les Fleurs du Mal.

[2] Bertelsen O. W. (2006). Tertiary Artefactness at the interface, In Fishwick, P. (ed.) Aesthetic Computing. MITPress.

[3] Bertelsen, O. W. and S. Pold (2004). Criticism as an approach to interface aesthetics. Proc. NordiCHI 2004. Tampere, Finland, ACM Press.

[4] Bolter, J. D. and D. Gromala (2003). Windows and mirrors: interaction design, digital art and the myth of transparency. Cambridge, MA, MIT-Press.

[5] Breinbjerg, M. (2003). At lytte til verden - mellem hermeneutik og erotik (To listen to the world - between hermeneutics and eroticism). Autograf - tidsskrift for ny musik, Aarhus Unge Tonekunstnere.

[6] Brewer, J., Kaye, J., Williams, A., Wyche, S. (2006). Sexual interactions: why we should talk about sex in HCI. CHI 'O6 Extended Abstracts ACM Press, 1695-1698.

[7] Crabtree, A., Hemmings, T., and Rodden, T. (2002). Patternbased support for interactive design in domestic settings. Proc. DIS '02. ACM Press.
[8] Dencik, L (2001) Living in Modern Times: Implications for the Lives of Children and their Families. Opening plenary lecture at the International Conference of the International Commission on Couple and Family Relations, Stockholm. http://www.baff.ruc.dk/Reports/pdf_reports/no4.pdf

[9] Ehn. P., Eriksson, B., Eriksson, M., Frenckner, K., and Sundblad, Y. (1984). Utformning av Datorstödd Ombrytning för dagstidninger (Development of Computer Supported Typesetting for Newspapers). Graphic Systems, Göteborg.

[10] Grönvall, E., Marti, P., Pollini, A., Rullo, A., Bertelsen, O. W. (2005). Palpable Time for Heterogeneous Care Communities. Proc. Critical Computing, Aarhus 2005. ACM Press.

[11] Hochschild, A.R. (1999). The time trap - when work becomes home and home becomes work. NY: Amacom.

[12] Iversen, O. S., Kanstrup, A., and Petersen M. G. (2004). On Emancipation, Quality \& Democracy in Design. Proc of NordiCHI 2004.

[13] LeVay, S. \& Valente, S. M. (2006). Human Sexuality. Sunderland MA: Sinauer Associates.

[14] McCarthy, J. and Wright, P. (2004). Technology as Experience. MIT Press.

[15] Mackay, J. (2000). Global Sex: Sexuality and sexual practices around the world. 5th Congress of the European Federation of Sexology, Berlin, 29 June - 2 July 2000. http://www2.hu-berlin.de/sexology/GESUND/ARCHIV/ PAP_MAC.HTM\#S3

[16] Nagel, K. S., Hudson, J. M., and Abowd, G. D. 2004. Predictors of availability in home life context-mediated communication. Proc. CSCW '04. ACM Press, 497-506.

[17] Petersen, M. G. (2007). Squeeze: Designing for Playful Experiences among co-located People in Homes. CHI2007 (work in progress). ACM Press.

[18] Petersen, M. G. (2004). Remarkable Computing - the Challenge of Designing for the Home. CHI '04 Extended Abstracts s, ACM Press, pp. 1445-1448.

[19] Petersen, M.G., Iversen, O., Krogh, P., Ludvigsen, M. (2004). Aesthetic Interaction - A pragmatic aesthetics of interactive systems. Proc DIS2004, ACM Press.

[20] Politiken (Article in Danish Newspaper) 17.1.2006 "A TV in the Bedroom stops the lust".

[21] Shusterman, R. (2006). Aesthetic Experience: From Analysis to Eros. J. of Aest. \& Art Crit. 64:2, Spring 2006.

[22] Udsen, L.E. and Jørgensen, A.H. (2005). The aesthetic turn: unravelling recent aesthetic approaches to human-computer interaction. Digital Creativity, 16 (4): 205-216.

[23] Ventegodt, S. (1998). Sex and the Quality of Life in Denmark Archives of Sexual Behaviour, 27(3), pp 295-230. 